\title{
Effects of combined infrared and hot-air drying on ginsenosides and drying characteristics of Panax notoginseng (Araliaceae) roots
}

\author{
Dalong J iang ${ }^{1}$, Yue Liư ${ }^{2 *}$, Zifan Lin ${ }^{3}$, Wenjie Wang ${ }^{1}$, Zhi'an Zheng ${ }^{1 *}$ \\ (1. College of Engineering, China Agricultural University, Beijing 100083, China; \\ 2. School of Electrical and Electronic Engineering Changchun University of Technology, Changchun, Jilin 130012 China; \\ 3. Department of Electrical and Electronic Engineering, University of Western Australia, Perth 6000, Australia)
}

\begin{abstract}
Exploring new drying technology can help to deal with the challenge of better preservation of rhizome medicinal materials in the traditional Chinese medicine industry. In current work, combined infrared and hot-air drying (IR-HAD) was employed to Panax notoginseng roots and its effect on drying kinetics, energy efficiency and quality, i.e., rehydration ratio $(R R)$, color parameters $\left(L^{*}, a^{*}, b^{*}\right)$, total color difference $(\Delta E)$, Panax notoginseng saponins (PNS) content, and ginsenosides content $\left(R_{1}, R_{\mathrm{g} 1}, R_{\mathrm{e}}, R_{\mathrm{d}}, R_{\mathrm{b} 1}\right)$ were evaluated. Hot air drying (HAD) was used as the control. Results showed that the increase in drying temperature significantly shortened drying time and reduced energy consumption. The shortest drying time of $43.0 \mathrm{~h}$ and lowest specific energy consumption of $15.9 \mathrm{~kW} \cdot \mathrm{h} /\left(\mathrm{kg}\right.$-water) were obtained by IR-HAD at $55^{\circ} \mathrm{C}$. The decrease of radiation distance and the increase of radiation power led to the shortening of drying time. However, high drying temperature resulted in large $\Delta E$ values, large collapse structure, and $R R$ of samples. The drying time of Panax notoginseng roots dried by IR-HAD at a drying temperature of $50^{\circ} \mathrm{C}$ was shorter $(15.5 \%)$ than HAD dried at the same drying temperature. The contents of $R_{1}, R_{\mathrm{g} 1}, R_{\mathrm{e}}, R_{\mathrm{b} 1}$, and PNS were higher when the samples were dried by IR-HAD than those dried by HAD at the same temperature of $50^{\circ} \mathrm{C}$. Moreover, the IR-HAD dried samples shortened $15.5 \%$ drying time and saved $22.1 \%$ energy consumption compared with HAD. Therefore, the optimal process condition was Panax notoginseng roots under IR-HAD at drying temperature of $50^{\circ} \mathrm{C}$, radiation distance of $12 \mathrm{~cm}$ and radiation power of $1350 \mathrm{~W}$, which can shorten drying time, maintain high ginsenosides contents and satisfactory apparent qualities.
\end{abstract}

Keywords: Panax notoginseng (Burk.) F. H. Chen (Araliaceae) roots, infrared and hot air drying, drying kinetics, energy consumption, quality

DOI: $10.25165 /$ j.ijabe.20221501.6210

Citation: Jiang D L, Zheng Z A. Effects of combined infrared and hot-air drying on ginsenosides and drying characteristics of Panax notoginseng (Araliaceae) roots. Int J Agric \& Biol Eng, 2022; 15(1): 267-276.

\section{Introduction}

Panax notoginseng (Burk.) F. H. Chen roots are the perennial herbs of the genus Araliaceae, which is one of the commonly used as a medicine called Xueshuantong due to its saponin constituents ${ }^{[1]}$. The total planting area of Panax notoginseng in Yunnan Province, China was over $3000 \mathrm{hm}^{2}$ in $2020^{[2]}$. Panax notoginseng roots were rich in nutrients, containing saponins (PNS), polysaccharides, dencichine, amino acids, flavonoids, phytosterols, cyclopeptides, saccharides, fatty acids, volatile oils, aliphatic acetylene hydrocarbons, and trace elements ${ }^{[3-6]}$. In addition, PNS are the main active compounds of Panax notoginseng, and more than 100 PNS have been isolated and identified, including ginsenosides, notoginsenosides, and gypenosides. Five saponins,

\section{Received date: 2020-10-09 Accepted date: 2021-05-02}

Biographies: Dalong Jiang, PhD candidate, research interest: intelligent drying equipment research and development, Email: 3473972630@qq.com; Zifan Lin, $\mathrm{PhD}$ candidate, research interest: power electronics, embedded system and microgrids, Email: zifan.lin@uwa.edu.au; Wenjie Wang, master candidate, research interest: agricultural machinery research and development, Email: wangwenj0327@163.com.

*Corresponding author: Yue Liu, PhD, Associate Professor, research interest: nonlinear dynamics, control theory and control engineering, chaos control and anti-control, Tel: +86-431-85716441, Email: lycn81@163.com; Zhi’an Zheng, $\mathrm{PhD}$, Associate Professor, research interest: agricultural machinery research and development. College of Engineering, China Agricultural University, Beijing 100083, China. Tel: +86-10-62736883, Email: zhengza@cau.edu.cn. i.e., ginsenoside $R_{\mathrm{b} 1}$, ginsenoside $R_{\mathrm{g} 1}$, notoginsenoside $R_{1}$, ginsenoside $R_{\mathrm{d}}$ and ginsenoside $R_{\mathrm{e}}$, are most often used in pharmacy and medicine ${ }^{[7]}$. Importantly, ginsenoside $R_{1}$ is an important component of Xueshuantong capsule ${ }^{[8]}$. The sum of $R_{1}$, $R_{\mathrm{g} 1}, R_{\mathrm{e}}, R_{\mathrm{d}}$, and $R_{\mathrm{b} 1}$ contents is equal to the PNS value. In recent years, dried roots were also used as a raw material in the manufacture of health products, such as Panax notoginseng tea and Panax notoginseng wine ${ }^{[9]}$.

Hot air drying (HAD) is still the most frequently used drying method due to its convenient operation, simple equipment, and less investment ${ }^{[10-12]}$. However, there are still some issues of traditional air drying, such as low drying efficiency due to the direction difference of material internal temperature and moisture gradient, which are not conducive to heat transfer and moisture evaporation $^{[13-15]}$. In addition, in air drying process, the samples suffer more heat damage in the long-term thermal transfer process, resulting in poor quality ${ }^{[16]}$. Freeze-Drying (FD) provides dried Panax notoginseng roots with good color and minimal changes in the medicinal ingredients compared to the sample dried by $\mathrm{HAD}^{[17]}$ But the high cost of FD hinders its large-scale application ${ }^{[18,19]}$. Moreover, Chen et al. ${ }^{[20]}$ reported that by combining Radio Frequency (RF) with HAD by either applying simultaneously or applying one after another, the in-shell hazelnuts (Corylus avellana L.) drying efficiency can be improved by reducing the drying time by at least half. Zhang et al. ${ }^{[21]}$ also showed that Hot Air-assisted Radio Frequency (HARF) treatments could strongly reduce the drying time of walnut samples compared to Hot Air (HA) heating 
alone. Though RF and microwave (MW) heating had some advantages, such as material heating fast, moisture content self-balance, energy penetration depth, their wide application were limited due to the problems of heat migration and ignition ${ }^{[21,22]}$. Therefore, suitable drying methods and optimum drying conditions are important to enhance the drying process and obtain high quality of dried Panax notoginseng roots ${ }^{[16]}$.

Infrared (IR) radiation heating, a potential drying method, can penetrate the material surface (2-4 mm depth) including rice ${ }^{[23]}$, apple $^{[24]}$, green peas ${ }^{[25]}$, strawberry ${ }^{[26]}$, cucumber ${ }^{[27]}$, sweet potato $^{[28]}$, and carrot ${ }^{[29]}$ and be converted into thermal energy by molecular vibration to heat the material. This molecular-level heating results in reduced drying time with good product quality as compared with hot air drying ${ }^{[30,31]}$. Despite advantages, due to the limited penetration depth, IR energy is usually applied in combination with other drying methods, such as hot air, microwave and vacuum drying ${ }^{[30,31]}$. Many studies have reported that a higher drying rate and better quality of food materials were obtained in combined IR and hot air heating compared to hot air or IR heating alone due to the synergistic effect ${ }^{[30-33]}$.

However, there is no published research on the influence of different radiation temperatures, radiation distances and radiation powers on Panax notoginseng roots drying. Hence, the objectives of this research were to evaluate the effects of combined infrared and hot-air drying (IR-HAD) i.e. constant drying temperature, constant radiation distance and radiation power on 1) the drying characteristics of whole Panax notoginseng roots; 2) quality attributes, such as color $\left(L^{*}, a^{*}, b^{*}, \Delta E\right)$, rehydration ratio $(R R)$, ginsenosides contents $\left(R_{1}, R_{\mathrm{b} 1}, R_{\mathrm{d}}, R_{\mathrm{e}}, R_{\mathrm{g} 1}, \mathrm{PNS}\right)$, microstructure, and specific energy consumption.

\section{Materials and methods}

\subsection{Materials}

The fresh three-year-old cultivated Panax notoginseng (Burk.) F.H. Chen roots were purchased from Wenshan City, Yunnan Province, China. The roots were stored in a refrigerator at $(4 \pm 1)^{\circ} \mathrm{C}$ and $(90 \pm 5) \%$ relative humidity prior to processing. Raw roots were washed with tap water to remove the sand and dirt on the surface, the water on its surface was eliminated by blowing ambient air. The average initial moisture content of ginger samples was $(2.19 \pm 0.10) \mathrm{g} / \mathrm{g}$ d.b., which was determined by vacuum drying at $70^{\circ} \mathrm{C}$ until the weight was constant ${ }^{[18]}$.

\subsection{Experimental equipment and design}

A $1.5 \mathrm{~kW}$ IR-convective dryer (Senttech Infrared Science and Technology Co., Ltd., Taizhou, China) was used in this study (Figure 1).

The IR lamps are parallel to the material tray. Three radiation distances, between the IR lamps and the surface of the material, of 80,120 , and $160 \mathrm{~mm}$ were tested. The drying chamber dimension was $355 \mathrm{~mm} \times 410 \mathrm{~mm} \times 200 \mathrm{~mm}$. To obtain the maximum IR energy absorption, the system was designed with an IR wavelength band of $0.75-4.00 \mu \mathrm{m}^{[33]}$. Three medium-wave (2-4 $\left.\mu \mathrm{m}\right)$ IR lamps with radiation power of 450,225 , and $225 \mathrm{~W}$ and three short-wave $(0.75-2.00 \mu \mathrm{m})$ IR lamps with radiation power of 450, 450, and $225 \mathrm{~W}$, respectively, were staggered at the top of the drying chamber. The ambient air was impinged onto the six equidistant IR lamps through 18 circular nozzles (with an inner diameter of $10 \mathrm{~mm}$ and air velocity at the drying region of $1 \mathrm{~m} / \mathrm{s}$ ) in six rows to achieve forced convection of radiant heat. A thermal sensor (PT100, TD Sensors Technology, China) was put at the top surface of the material tray to measure the air temperature and to control the temperature within $0.1{ }^{\circ} \mathrm{C}$ in the drying chamber. An electricity meter (DTS7178, Shanghai Mingrong Electric Co., Ltd, China) was installed at the output of the machine to record the energy consumption during the drying process. The experimental design for drying temperature $(T)$, radiation distance $\left(R_{d}\right)$, and radiation power $\left(R_{p}\right)$ is listed in Table 1 .

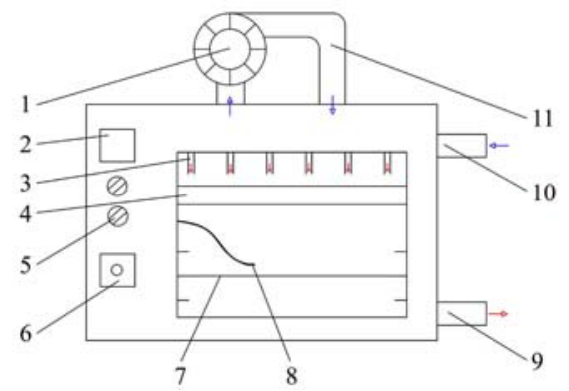

1. Centrifugal blower 2. Touch screen 3. Spray nozzle 4. Infrared heating tube 5. Power supply control switch 6. Speed control knob 7. Material tray 8. Temperature sensor 9. Wet discharging port 10. Air inlet port 11. Air inlet pipe

Note: arrows represent the direction of air flow.

Figure 1 Schematic diagram of combined medium- and short-wave infrared and hot air impingement drying equipment

Table 1 Experimental design for infrared and hot air drying and hot air drying of Panax notoginseng roots

\begin{tabular}{cccccc}
\hline Experiment number & Drying process & $T /{ }^{\circ} \mathrm{C}$ & $\mathrm{Rd} / \mathrm{cm}$ & $\mathrm{Rp} / \mathrm{W}$ & $t_{T} / \mathrm{h}$ \\
\hline 1 & Control (raw, non-treated) & -- & -- & -- & \\
2 & IR-HAD & 40 & 12 & 1350 & 66.8 \\
3 & IR-HAD & 45 & 12 & 1350 & 50.5 \\
4 & IR-HAD & 50 & 12 & 1350 & 46.5 \\
5 & IR-HAD & 55 & 12 & 1350 & 43.0 \\
6 & IR-HAD & 50 & 8 & 1350 & 43.0 \\
7 & IR-HAD & 50 & 16 & 1350 & 59.7 \\
8 & IR-HAD & 50 & 12 & 675 & 50.0 \\
9 & IR-HAD & 50 & 12 & 2025 & 35.9 \\
10 & HAD* & 50 & -- & & 55.0 \\
\hline
\end{tabular}

Note: Relative humidity (RH): $12 \%$; Airflow rate $(v): 0.3 \mathrm{~m} / \mathrm{s}$. IR-HAD Infrared and Hot Air Drying; HAD: Hot Air Drying; $T$ : Temperature, ${ }^{\circ} \mathrm{C} ; t_{T}$ : drying time, h; Rd: Radiation distance, cm; Rp: Radiation power, W. The same as below.

The Schematic diagram of the convective hot air dryer used for Panax notoginseng roots drying is shown in Figure 2, which was described in detail in Reference [11].
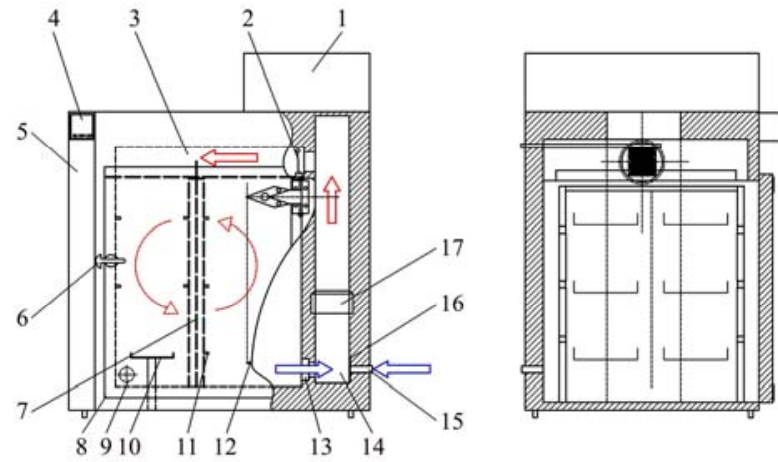

1. Humidification water tank 2. Wet curtain 3. Air bellow assembly 4. Human machine interface 5. Distribution box 6. Doorknob 7. Fan support 8. Drying chamber door 9. Moisture removing centrifugal fan 10. Weighing module 11. Tray support 12. Door hinge 13. Return air flue 14. Electric heating assembly 15. Inlet air pipe 16. Iron ore net 17. Axial flow fan

Note: Arrows represent the direction of air flow.

Figure 2 Schematic diagram of the convective hot air dryer used for Panax notoginseng roots drying 
The hot air drying temperature, relative humidity and airflow rate were set as $50^{\circ} \mathrm{C}, 12 \%$, and $0.3 \mathrm{~m} / \mathrm{s}$, respectively, according to the pre-experiment. The drying time, ginsenoside contents, color, $R R$, and microstructure of dried samples were evaluated.

\subsection{Determination of drying characteristics of Panax} notoginseng roots

The moisture ratio (MR) of the Panax notoginseng roots during drying was calculated using the following equation ${ }^{[19]}$ :

$$
\mathrm{MR}=\frac{M_{t}-M_{e}}{M_{0}-M_{e}}
$$

where, $M_{t}$ indicates the moisture content at a particular drying time ( $t$ ), $\mathrm{g} \mathrm{H}_{2} \mathrm{O} / \mathrm{g}$ d.b.; $M_{0}$ indicates the initial moisture content, $\mathrm{g} \mathrm{H}_{2} \mathrm{O} / \mathrm{g}$ d.b.; $M_{\mathrm{e}}$ indicates the equilibrium moisture content, $\mathrm{g} \mathrm{H}_{2} \mathrm{O} / \mathrm{g}$ d.b.

When the equilibrium moisture content $M_{e}$ is relatively small compared to $M_{t}$ or $M_{0}$, Equation (1) can be written in a simplified form $^{[19]}$ as

$$
\mathrm{MR}=\frac{M_{t}}{M_{0}}
$$

The drying rate of the Panax notoginseng roots under various drying conditions was calculated according to the following equation $^{[34,35]}$ :

$$
\mathrm{DR}=\frac{M_{t 1}-M_{t 2}}{t_{2}-t_{1}}
$$

where, $M_{t 1}$ and $M_{t 2}$ indicate the moisture contents, $\mathrm{g} \mathrm{H}_{2} \mathrm{O} / \mathrm{g}$ d.b. of Panax notoginseng roots at time $t_{1}$ and $t_{2}$, respectively; $t_{1}$ and $t_{2}$ indicate drying times, $\mathrm{h}$.

\subsection{Determination of color changes during drying of Panax notoginseng roots}

The color of cross-sections of fresh and dried Panax notoginseng roots was measured using a D65 colorimeter (WR-10, Shenzhen Weifu Photoelectric Technology Co., Ltd., China) with standard illuminant D65 and observer $10^{\circ[36]}$. At least six measurements at different positions were made for each sample. The color was expressed in CIE $L^{*} a^{*} b^{*}$ scale, where parameter $L^{*}$ indicates white or black, parameter $a^{*}$ indicates red or green, and parameter $b^{*}$ indicates yellow or blue color. The index of total color change $(\Delta E)$ was calculated from the following equation $^{[36]}$.

$$
\Delta E=\sqrt{\left(L^{*}-L_{0}^{*}\right)^{2}+\left(a^{*}-a_{0}^{*}\right)^{2}+\left(b^{*}-b_{0}^{*}\right)^{2}}
$$

where, $\Delta E$ indicates the total color change between fresh and dried roots; $L_{0}{ }^{*}, a_{0}{ }^{*}$, and $b_{0}{ }^{*}$ indicate the color parameters of fresh roots; $L^{*}, a^{*}$, and $b^{*}$ indicate the color parameters of dried samples.

\subsection{Determination of rehydration ratio of dried Panax notoginseng roots}

The rehydration ratio of dried Panax notoginseng was determined according to the method described by Liu et al. ${ }^{[37]}$ with slight modifications. The rehydration process was conducted at a constant temperature of $40^{\circ} \mathrm{C}$. About $10 \mathrm{~g}$ of dried roots were immersed in distilled water for $24 \mathrm{~h}$. After this time, the rehydrated samples were removed from the water and blotted with a paper towel to remove excess water from the sample surface. The mass of Panax notoginseng roots was monitored using an electronic balance (SP402, Ohaus Co., New Jersey, USA) with an accuracy of $\pm 0.01 \mathrm{~g}$. The results were averaged over 6 measurements. Rehydration ratio $(R R)$ was defined as the ratio of sample mass after rehydration to the mass of the dried sample before rehydration and calculated according to Equation (5) ${ }^{[36]}$ :

$$
\mathrm{RR}=\frac{\text { Weight of sample after rehydration }(\mathrm{g})}{\text { Weight of dry sample }(\mathrm{g})}
$$

\subsection{Scanning electron microscope (SEM) observations}

The microstructure of vertical cross-sections of the dehydrated roots was observed using a scanning electron microscope (SEM) (S-3500, Hitachi, Tokyo, Japan) at an accelerating voltage of $20 \mathrm{kV}$ according to the method described in the literature ${ }^{[38]}$. The samples were sputter-coated (SC7640, Quorum Technologies Ltd., Newhaven, UK) with an additional thin layer $(\sim 10 \mathrm{~nm})$ of gold $^{[39]}$. The images of representative areas were saved for further analysis. Images were observed at magnifications $\times 100$.

\subsection{Determination of ginsenosides contents}

The ginsenosides contents $R_{\mathrm{g} 1}, R_{\mathrm{e}}, R_{\mathrm{b} 1}, R_{\mathrm{d}}$, Panax notoginseng ginsenoside $R_{1}$ and Panax notoginseng saponins (PNS) were determined using high-performance liquid chromatography (HPLC) (Waters e2695, USA) at $203 \mathrm{~nm}$ following the methodology described by Qu et al. ${ }^{[34]}$ with some modifications. The standards of ginsenoside $R_{1}, R_{\mathrm{g} 1}, R_{\mathrm{e}}, R_{\mathrm{b} 1}$ and $R_{\mathrm{d}}$ were purchased from the Chinese Medical and Biological Products Institute (Beijing, China). The dried samples under different drying conditions were crushed and then passed through a 40 -mesh sieve with a $0.425 \mathrm{~mm}$ aperture. The mass of $400 \mathrm{mg}$ of the sample powder was accurately weighed on an electronic balance (AB135-S, Mettler Toledo, Greifensee, Switzerland) with an accuracy of $0.01 \mathrm{mg}$. The sample powder was placed in a $200 \mathrm{~mL}$ flask of a Soxhlet's extractor and $100 \mathrm{~mL}$ of $70 \%(\mathrm{v} / \mathrm{v})$ ethanol solution was added. The mixture was refluxed in a water bath $\left(35^{\circ} \mathrm{C}\right)$ for $24 \mathrm{~h}$ to extract the ginsenosides and then the extract was evaporated for further analysis. A Prevail reverse-phase C8 column (Shimadzu, Tokyo, Japan) $(150.0 \mathrm{~mm} \times 4.6 \mathrm{~mm} \times 5 \mu \mathrm{m})$ was used to separate ginsenosides in a binary solvent consisting of acetonitrile $\left(\mathrm{CH}_{3} \mathrm{CN}\right.$, solvent $\left.\mathrm{A}\right)$ and distilled water (solvent $\mathrm{B}$ ) with a gradient elution: 0-25 min, 19\%-20\% A, $81 \%-80 \%$ B; $25-70$ min, $20 \%-40 \%$ A, $80 \%-60 \%$ B; $70-75 \mathrm{~min}, 40 \%-19 \%$ A, $60 \%-81 \%$ B. The column was then washed with $100 \%$ of solvent $\mathrm{A}$ for $15 \mathrm{~min}$ at a flow rate of $1.5 \mathrm{~mL} / \mathrm{min}$. All the above experiments were performed in triplicate and the average values were used.

\subsection{Determination of specific energy consumption}

The specific energy consumption (SEC, $\mathrm{kW} \cdot \mathrm{h} /(\mathrm{kg}$-water)), for each drying condition, was estimated considering the drying time involved and energy utilization by the dryer, as Equation $(6)^{[36]}$.

$$
\mathrm{SEC}=\frac{1000 \mathrm{~W}}{m_{0} \phi_{0}-m_{1} \phi_{i}}
$$

where, $m_{0}$ and $m_{i}$ represent the mass of samples before and after drying, g; $\phi_{0}$ and $\phi_{i}$ are moisture content before and after drying (w.b., g/g); $W$ represents the power energy consumed during the drying process, $\mathrm{kW} \cdot \mathrm{h}$; SEC is the specific energy consumption, $\mathrm{kW} \cdot \mathrm{h} /(\mathrm{kg}$-water) $(\mathrm{kW} \cdot \mathrm{h} /(\mathrm{kg}$-water) represents the electrical energy consumed by removing water per unit mass).

\subsection{Statistical analyses}

To determine the differences among samples dried under different drying conditions the data were analyzed by LSD multiple comparison test using SPSS software (Version 21.0, SPSS Inc., Chicago, IL, USA). The significance of differences was tested at a $5 \%$ probability level $(p<0.05)$. The correlations between parameters were analyzed using Pearson's correlation test.

\section{Results and discussion}

\subsection{Drying characteristics}

The changes in moisture ratio versus drying time $(t)$ are shown in Figure $3 \mathrm{a}$, while the changes in drying rate versus moisture content are shown in Figure 3b. The drying time decreased and 
the drying rate increased with the increase of the drying temperature by IR-HAD. When IR-HAD was conducted at different drying temperatures of $40^{\circ} \mathrm{C}, 45^{\circ} \mathrm{C}, 50^{\circ} \mathrm{C}$, and $55^{\circ} \mathrm{C}$, constant radiation distance of $12 \mathrm{~cm}$ and constant radiation power of $1350 \mathrm{~W}$, the drying times were $66.8,50.5,46.5$, and $43.0 \mathrm{~h}$, respectively. The drying time of Panax notoginseng roots dried by IR-HAD at a drying temperature of $50^{\circ} \mathrm{C}$ was much shorter $(15.5 \%)$ than HAD at the same drying temperature (Figure 3a). It is likely that an acceleration intermolecular friction of moisture due to the absorption of the electromagnetic energy could result in high drying efficiency ${ }^{[40,41]}$. Similar findings have been reported by Roknul et al. ${ }^{[42]}$ in IR and HA experiments of stem lettuce slices. Zhang et al. ${ }^{[43]}$ also found a similar phenomenon in the infrared combined with hot air drying sponge gourd (Luffa cylindrical) slices.

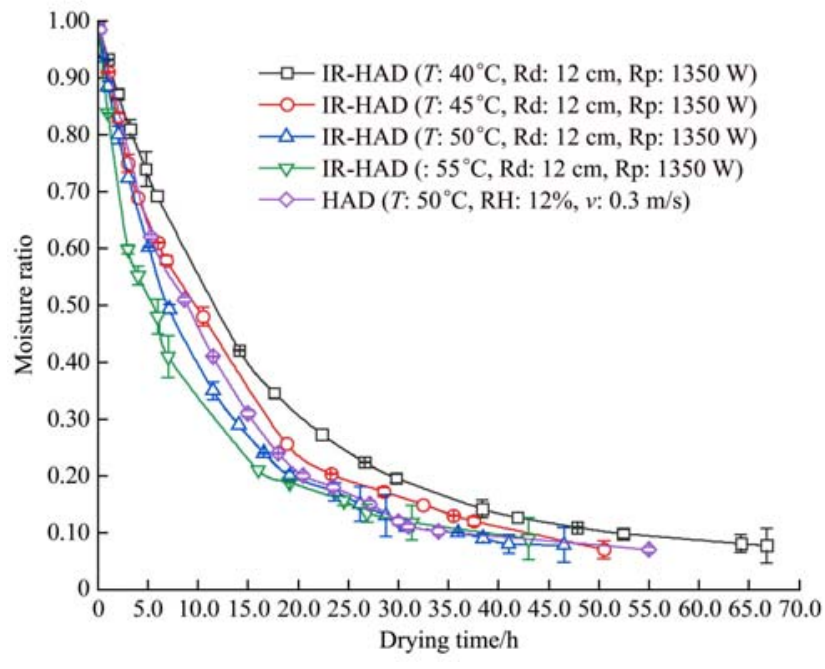

a. Changes in moisture ratio versus drying time

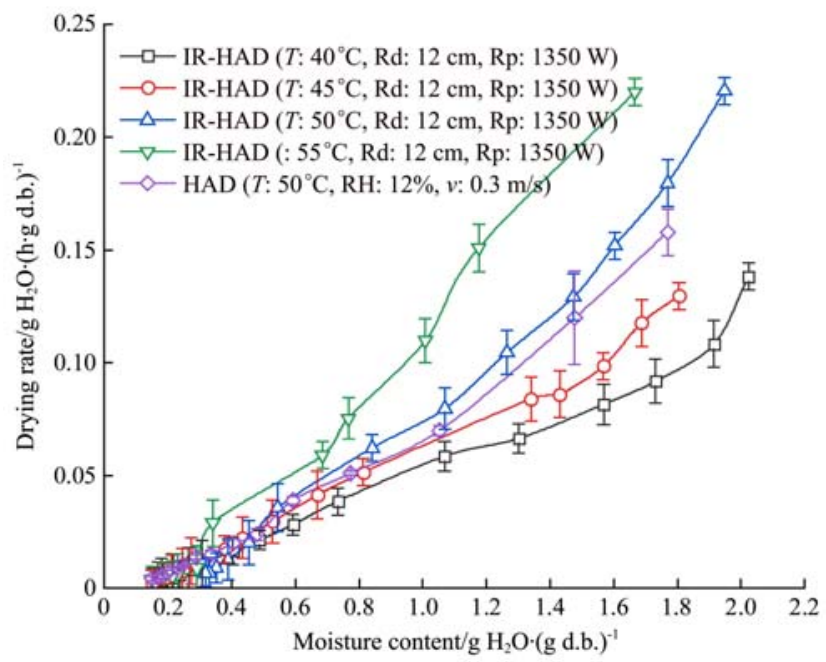

b. Drying rate versus moisture content

Note: IR-HAD: Infrared and Hot Air Drying; HAD: Hot Air Drying; T: Temperature, ${ }^{\circ} \mathrm{C}$; Rd: Radiation distance, cm; Rp: Radiation power, W; $\mathrm{RH}$ : Relative humidity, \%; $v$ : Airflow rate, $\mathrm{m} / \mathrm{s}$, the same as below.

Figure 3 Drying characteristic curves during IR-HAD and HAD of Panax notoginseng roots

The drying rate decreased continuously with the decrease in moisture content. Constant drying rate did not occur during IR-HAD of Panax notoginseng roots. This result was inconsistent with the previous works of Wang et al. ${ }^{[44]}$, who found that there were typical three distinct drying periods, a short warm-up period, in the beginning, followed by a constant period and toward the end a long falling drying rate period, which is in accordance with the drying of lemon slices for all four drying temperatures. A steep curve indicates high drying rates occurred at the initial drying stage, while a less steeper curve indicates a much lower drying rate in the final stage of drying. Nevertheless, the drying rate decreased significantly faster in the final stage of IR-HAD than in the final stage of HAD. This phenomenon is that the drying speed is too fast in the early stage, which leads to the serious damage of the material structure and the obstruction of the migration path of water molecules, thus reducing the drying rate. Ranjan et al. ${ }^{[45]}$ showed that the drying rate of banana slices was significantly affected by shrinkage during drying.

Figure 4 showed that at the same drying temperature and radiation power, a decrease in radiation distance resulted in a corresponding reduction in the drying time. The reason might be that shorter radiation distance corresponded to more IR energy absorption by samples ${ }^{[23,26,46,47]}$. IR-HAD at drying temperature of $50^{\circ} \mathrm{C}$, radiation power of $1350 \mathrm{~W}$ and radiation distance of 8 , 12 , and $16 \mathrm{~cm}$ took 43.0, 46.5, and $59.7 \mathrm{~h}$, respectively. Research by Seyed-Hassan et al. showed that increasing infrared intensity and decreasing airflow velocity and emitter-sample distance led to higher $D_{\text {eff }}$ values in infrared drying ${ }^{[48]}$. The findings revealed that the energy of infrared radiation decayed significantly with the extension of distance, and its penetrability was limited, which was confirmed in the drying rate curves of Figure 4b.

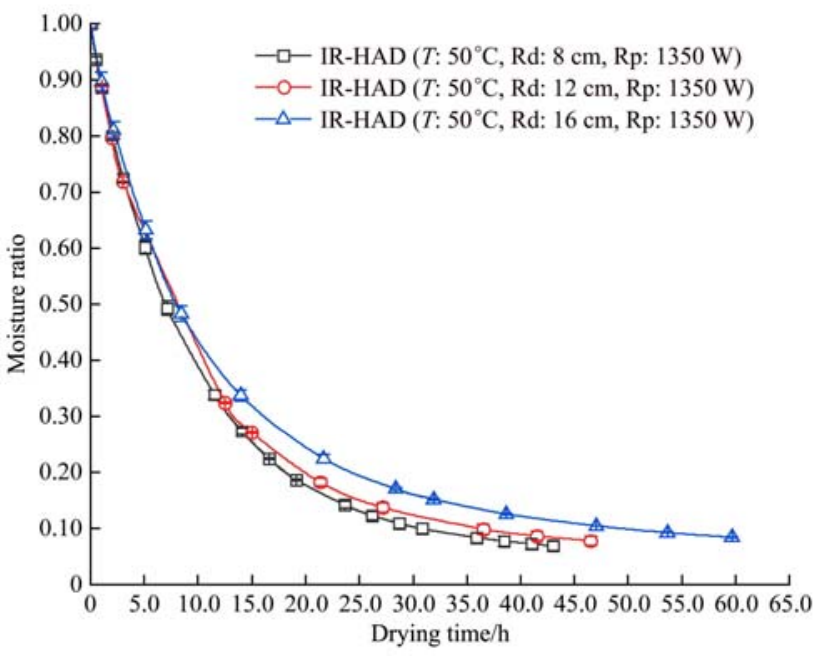

a. Changes in moisture ratio versus drying time

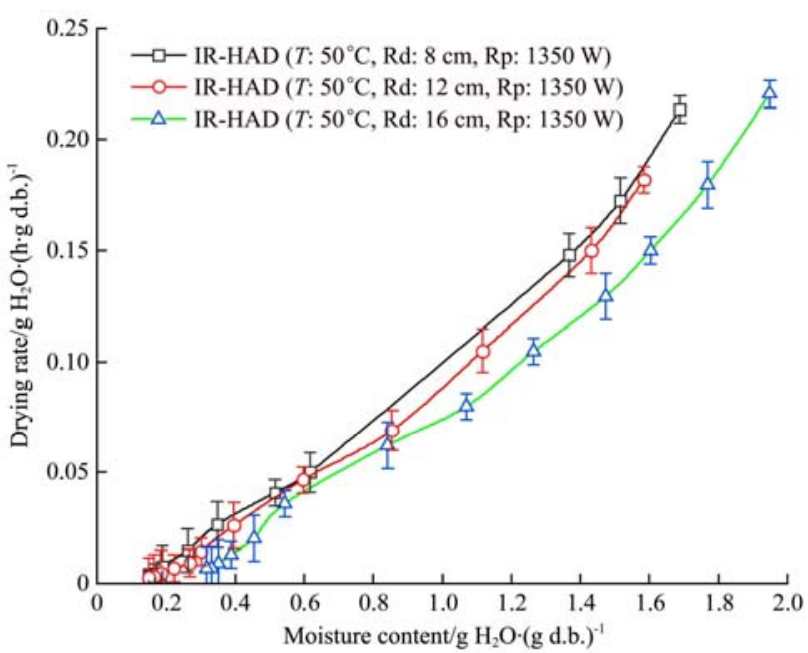

b. Drying rate versus moisture content

Figure 4 Drying characteristic curves during IR-HAD of Panax notoginseng roots 
Drying curves of Panax notoginseng roots at different radiation power are shown in Figure 5. At the same drying temperature of $50^{\circ} \mathrm{C}$ and radiation distance of $12 \mathrm{~cm}$, an increase in radiation power resulted in a corresponding reduction in the drying time. The total drying times taken for samples using IR-HAD drying required at 675,1350 , and $2025 \mathrm{~W}$ were $50.0,46.5$, and $35.9 \mathrm{~h}$, respectively. The radiation power was directly proportional to the radiation energy density. The higher the radiation power is, the higher the heat energy radiated out per unit time, thus speeding up the drying rate and shortening the drying time. Tysen et al. reported that the most substantial shortenings of drying time were obtained for the lowest grammages and the highest radiator power level used infrared radiation for heating the web $^{[49]}$. Ghaboos et al. ${ }^{[50]}$ also found in the study of dehydration characteristics of pumpkin (Cucurbita moschata) by infrared vacuum drying in a combined drying system, drying time was significantly shortened as infrared radiation power increased from 204 to $272 \mathrm{~W}$. Or more likely, the increase of radiation power may cause the wavelength to shift to $2 \mu \mathrm{m}$, which is conducive to enhancing the penetration depth. This is similar to the results obtained by Zhang et al. ${ }^{[43]}$

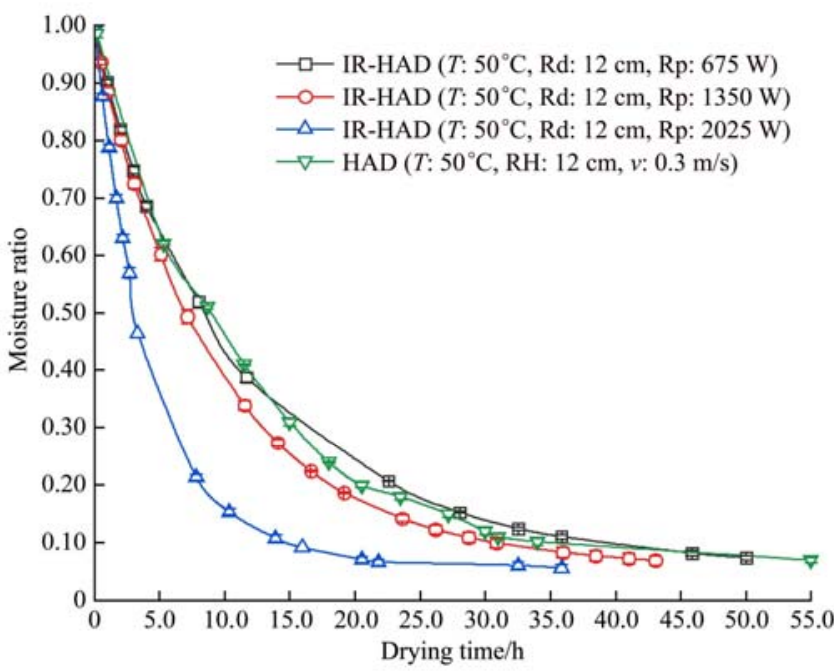

a. Changes in moisture ratio versus drying time

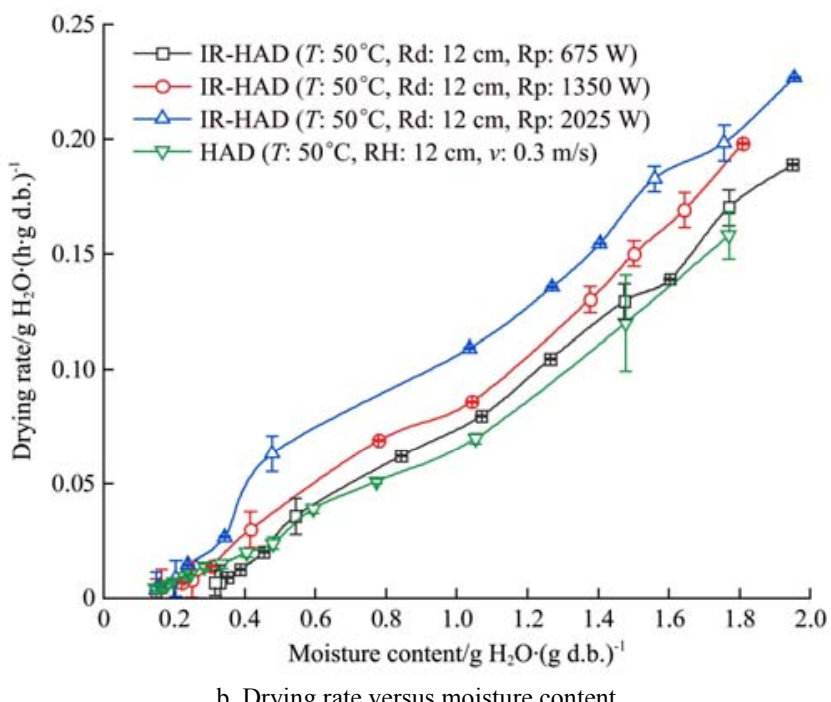

b. Drying rate versus moisture content

Figure 5 Drying characteristic curves during IR-HAD of Panax notoginseng roots

In summary, IR radiation drying has higher heat and mass transfer coefficients than HAD, which enhances heat flux and removal of free bound water, promoting drying process ${ }^{[51]}$.

\subsection{Color changes of Panax notoginseng roots during drying}

Color is one of the most important indicators in the evaluation of the quality of fruit and vegetable dried products, which influences customers' acceptability and the market value of products $^{[36,52]}$. Table 2 shows the effects of the different drying conditions on the color parameters $\left(L^{*}, a^{*}, b^{*}, \Delta E\right)$ of Panax notoginseng roots. The lightness $\left(L^{*}\right)$, redness $\left(a^{*}\right)$, and yellowness $\left(b^{*}\right)$ of raw and dried samples ranged from 44.4 to 60.8 , 0.8 to 4.3 , and 17.3 to 43.3 , respectively. The values of parameter $L^{*}$ of Panax notoginseng roots gradually decreased, while the values of parameter $a^{*}$, as well as the index of $\Delta E$, gradually increased with the increase in the drying temperature from $40^{\circ} \mathrm{C}$ to $55^{\circ} \mathrm{C}$ by IR-HAD. The results indicated that dried Panax notoginseng roots were darker and greener than the fresh samples. Most probably, it was related to the degradation of pigments or non-enzymatic Maillard browning ${ }^{[9]}$. The results are consistent with data reported for American ginseng ${ }^{[9,11]}$. Significantly, the IR-HAD dried samples at the same temperature $\left(50^{\circ} \mathrm{C}\right)$ were greener and had less color difference than HAD. Jiang et al. ${ }^{[35]}$ found a significant correlation between the $a^{*}$ value and the content of medicinal ingredients, which may be due to the transformation of saponin content after drying, resulting in the green value greater than that of fresh samples. Zhang et al. also found a similar phenomenon when drying Luffa slices, indicating that the introduction of infrared radiation can improve the color quality of the product ${ }^{[43]}$. The values of parameter $b^{*}$ increased with the increase in the drying temperature from $40^{\circ} \mathrm{C}$ to $70^{\circ} \mathrm{C}$. As is known, ginseng root is rich in starch and amino acids ${ }^{[53]}$, the starch could be translated into reducing sugar at the high drying temperature and it may cause the occurrence of the Maillard reaction and some oxidation reactions which cause more color differences ${ }^{[54]}$.

Table 2 Color parameters $\left(L^{*}, a^{*}, b^{*}\right)$ of raw and dried Panax notoginseng roots and total color difference $(\Delta E)$ among raw, IR-HAD and HAD samples

\begin{tabular}{|c|c|c|c|c|}
\hline Experiment & $L^{*}$ & $a^{*}$ & $b^{*}$ & $\Delta E$ \\
\hline $\begin{array}{l}\text { Control (raw, } \\
\text { non-treated) }\end{array}$ & $60.83 \pm 0.08^{\mathrm{a}}$ & $2.14 \pm 0.01^{\mathrm{bc}}$ & $43.33 \pm 0.02^{\mathrm{a}}$ & - \\
\hline $\begin{array}{l}\text { IR-HAD } 40^{\circ} \mathrm{C}, \mathrm{Rd} \\
12 \mathrm{~cm}, \mathrm{Rp} 1350 \mathrm{~W}\end{array}$ & $53.96 \pm 0.81^{\mathrm{b}}$ & $0.76 \pm 0.01^{\mathrm{c}}$ & $26.00 \pm 0.01^{\mathrm{b}}$ & $18.69 \pm 0.01^{\mathrm{i}}$ \\
\hline $\begin{array}{l}\text { IR-HAD } 45^{\circ} \mathrm{C}, \mathrm{Rd} \\
12 \mathrm{~cm}, \mathrm{Rp} 1350 \mathrm{~W}\end{array}$ & $50.76 \pm 0.62^{\mathrm{c}}$ & $1.05 \pm 0.01^{\mathrm{c}}$ & $24.90 \pm 0.05^{\mathrm{b}}$ & $21.03 \pm 0.05^{\mathrm{h}}$ \\
\hline $\begin{array}{l}\text { IR-HAD } 50^{\circ} \mathrm{C}, \mathrm{Rd} \\
12 \mathrm{~cm}, \operatorname{Rp} 1350 \mathrm{~W}\end{array}$ & $47.95 \pm 0.32^{\mathrm{def}}$ & $1.37 \pm 0.01^{\mathrm{c}}$ & $22.30 \pm 0.09^{\mathrm{c}}$ & $24.67 \pm 0.02^{\mathrm{f}}$ \\
\hline $\begin{array}{l}\text { IR-HAD } 55^{\circ} \mathrm{C}, \mathrm{Rd} \\
12 \mathrm{~m}, \mathrm{Rp} 1350 \mathrm{~W}\end{array}$ & $44.40 \pm 0.39^{\mathrm{g}}$ & $4.25 \pm 0.01^{\mathrm{a}}$ & $21.86 \pm 0.14^{\text {cd }}$ & $27.12 \pm 0.01^{\mathrm{c}}$ \\
\hline $\begin{array}{l}\text { IR-HAD } 50^{\circ} \mathrm{C}, \mathrm{Rd} \\
8 \mathrm{~cm}, \mathrm{Rp} 1350 \mathrm{~W}\end{array}$ & $45.7 \pm 0.51^{\mathrm{fg}}$ & $2.29 \pm 0.47^{\mathrm{bc}}$ & $17.32 \pm 0.12^{\mathrm{e}}$ & $30.09 \pm 0.03^{\mathrm{a}}$ \\
\hline $\begin{array}{l}\text { IR-HAD } 50^{\circ} \mathrm{C}, \mathrm{Rd} \\
16 \mathrm{~cm}, \mathrm{Rp} 1350 \mathrm{~W}\end{array}$ & $56.95 \pm 0.64^{\mathrm{g}}$ & $1.22 \pm 0.98^{c}$ & $21.70 \pm 0.21^{\mathrm{cd}}$ & $21.99 \pm 0.02^{\mathrm{g}}$ \\
\hline $\begin{array}{l}\text { IR-HAD } 50^{\circ} \mathrm{C}, \mathrm{Rd} \\
12 \mathrm{~cm}, \mathrm{Rp} 675 \mathrm{~W}\end{array}$ & $46.26 \pm 0.82^{\mathrm{efg}}$ & $1.32 \pm 0.85^{\mathrm{c}}$ & $21.55 \pm 0.39^{\mathrm{cd}}$ & $26.22 \pm 0.01^{\mathrm{e}}$ \\
\hline $\begin{array}{l}\text { IR-HAD } 50^{\circ} \mathrm{C}, \mathrm{Rd} \\
12 \mathrm{~cm}, \mathrm{Rp} 2025 \mathrm{~W}\end{array}$ & $48.3 \pm 1.21^{\mathrm{de}}$ & $1.39 \pm 0.11^{\mathrm{c}}$ & $20.00 \pm 1.51^{\mathrm{d}}$ & $26.49 \pm 0.02^{\mathrm{d}}$ \\
\hline $\mathrm{HAD} 50^{\circ} \mathrm{C}$ & $48.84 \pm 1.20^{\mathrm{cd}}$ & $3.60 \pm 0.84^{\mathrm{ab}}$ & $16.80 \pm 1.01^{\mathrm{e}}$ & $29.15 \pm 0.01^{\mathrm{cd}}$ \\
\hline
\end{tabular}
Note: Different letters in the same column indicate significant differences between samples $(p<0.05)$

As the radiation distance increased from 8 to $16 \mathrm{~cm}$, the $L^{*}$ value gradually increased, while the $a^{*}$ value and $\Delta E$ decreased gradually under the constant drying temperature of $50^{\circ} \mathrm{C}$ and the radiation power of $1350 \mathrm{~W}$. This may be due to the extension of radiation distance, the weakening of infrared radiation energy, the slow rise of internal temperature of materials, and the extension of 
drying time, thus reducing color deterioration. Similarly, Ya et al. ${ }^{[5]}$ reported that an increase in Fourier transform infrared spectroscopy (FT-IR) temperature decreased $L^{*}$ but increased $a^{*}$ values of dried kiwifruits. The $L^{*}$ value of Ju et al. ${ }^{[24]}$ was 82.97 when the radiation distance was $120 \mathrm{~mm}$, which was higher than that of other processing methods such as microwave vacuum drying (81.140) and hot air drying (75.860).

As the radiation power increased from 675 to $2025 \mathrm{~W}$, the $L^{*}$ and $a^{*}$ value gradually increased, while the $\Delta E$ initially decreased and then increased under the constant drying temperature of $50^{\circ} \mathrm{C}$ and the radiation distance of $12 \mathrm{~cm}$. Zhang et al. ${ }^{[43]}$ reported that thickness near to the optimized IR penetration depth showed a significant effect $(p<0.05)$ in maintaining better color, consistent with findings by Pekke et al. ${ }^{[56]}$ that more color browning occurred in thicker banana slices under IR drying. The change of color difference may also be the cumulative effect of temperature and time, i.e., heat accumulation.

\subsection{Changes in ginsenosides and Panax notoginseng saponins} (PNS) contents of Panax notoginseng roots during dying

The contents of ginsenosides $R_{1}, R_{\mathrm{g} 1}, R_{\mathrm{e}}, R_{\mathrm{d}}, R_{\mathrm{b} 1}$, and PNS of the Panax notoginseng roots under different drying conditions are shown in Figure 6. Drying temperature significantly influenced the contents of ginsenoside $R_{1}, R_{\mathrm{g} 1}, R_{\mathrm{e}}, R_{\mathrm{d}}, R_{\mathrm{b} 1}$, and PNS. The contents of ginsenoside $R_{\mathrm{g} 1}, R_{1}, R_{\mathrm{e}}$, and PNS increased and then decreased as IR-HAD drying temperature increased from 40 to $55^{\circ} \mathrm{C}$ under the constant radiation distance of $12 \mathrm{~cm}$ and radiation

power of $1350 \mathrm{~W}$. Nevertheless, the contents of ginsenoside $R_{\mathrm{d}}$ and $R_{\mathrm{b} 1}$ decreased gradually. The reason for this phenomenon can be the fact that ginsenosides are heat sensitive and can be hydrolyzed during prolonged drying at lower temperatures, i.e., 40 or $45^{\circ} \mathrm{C}$, as well as short drying at higher temperatures, i.e., $55^{\circ} \mathrm{C}^{[57]}$. The contents of $R_{\mathrm{g} 1}, R_{\mathrm{e}}, R_{\mathrm{b} 1}$, and PNS were higher when the samples were dried by IR-HAD at $50^{\circ} \mathrm{C}$ and radiation distance of $12 \mathrm{~cm}$ and radiation power of $1350 \mathrm{~W}$ than the fresh samples. Ginsenosides are commonly divided into two categories, namely neutral (including the ginsenosides $R_{\mathrm{b} 1}, R_{\mathrm{e}}, R_{\mathrm{g} 1}$, etc.) and acidic (including the ginsenosides $\mathrm{m}-\mathrm{Rb} 1, \mathrm{~m}-\mathrm{Rc}, \mathrm{m}-\mathrm{Rd}$, etc.) ${ }^{[58]}$. The acidic ginsenosides become unstable and may be transformed into neutral ginsenosides during thermal processing. In fact, $\mathrm{m}-\mathrm{Rb} 1$ can be converted into $R_{\mathrm{b} 1}$ and $\mathrm{m}-\mathrm{Rc}$ into Rc under certain drying conditions ${ }^{[59]}$. Furthermore, Rb1 can be degraded by heat into other substances. The contents of $R_{1}, R_{\mathrm{g} 1}, R_{\mathrm{e}}, R_{\mathrm{b} 1}$, and PNS were higher when the samples were dried by IR-HAD than the samples dried by $\mathrm{HAD}$ at the same temperature of $50^{\circ} \mathrm{C}$. Ning et al. also found that the far-infrared drying showed a faster drying rate, higher saponin content, lower color difference value, and a decrease in energy consumption than seen in hot-air drying ${ }^{[60]}$. Vishwanathan et al. reported that the IR dried carrot had higher (by $17 \%$ ) retention of carotenoid than hot air-dried sample ${ }^{[61]}$. The results showed that compared with convection drying, infrared radiation drying technology has great potential to reduce the loss of nutrient content.

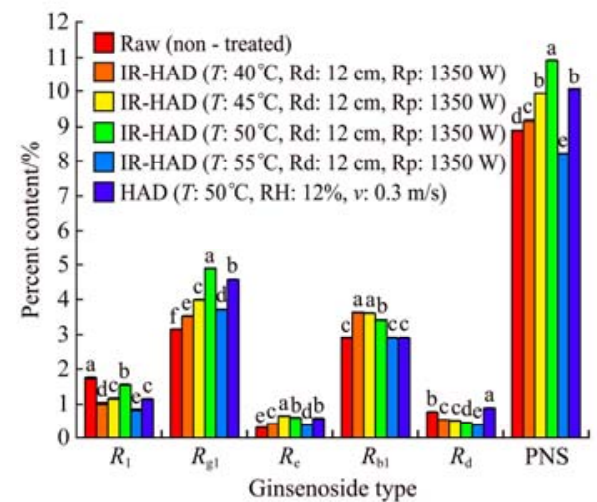

a. IR-HAD at different drying temperatures, constant radiation distance of $12 \mathrm{~cm}$ and constant radiation power of $1350 \mathrm{~W}$

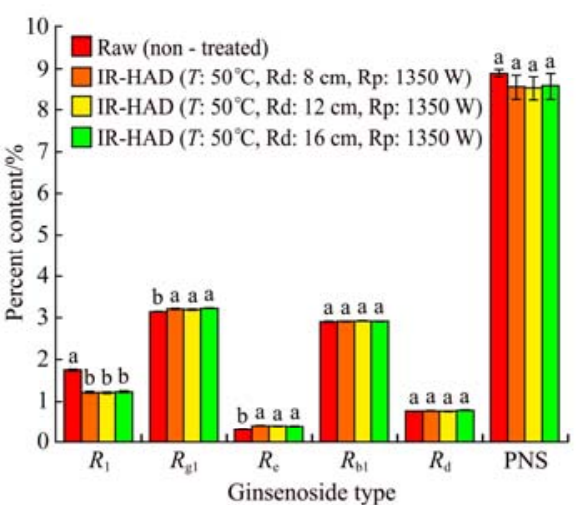

b. IR-HAD at different radiation distance, constant drying temperature of $50^{\circ} \mathrm{C}$ and constant radiation power of $1350 \mathrm{~W}$

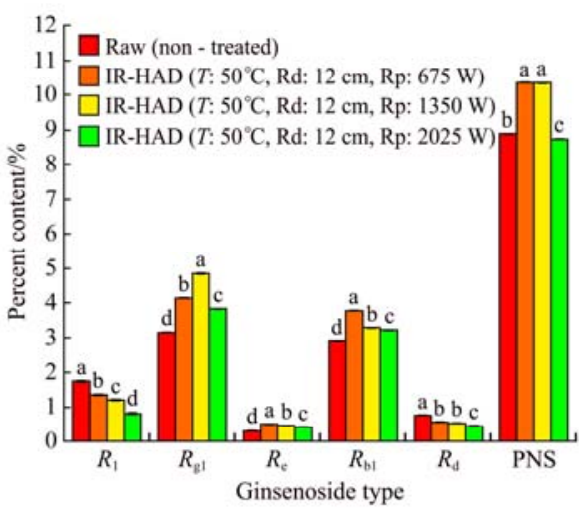

c. IR-HAD at different radiation power, constant drying temperature of $50^{\circ} \mathrm{C}$ and constant radiation distance of $12 \mathrm{~cm}$

Note: PNS: Content of Panax notoginsenosides, \%; $R_{1}$ : Content of notoginsenoside $R_{1}, \% ; R_{\mathrm{g} 1}$ : Content of ginsenoside $R_{\mathrm{g} 1}, \% ; R_{\mathrm{e}}$ : Content of ginsenoside $R_{\mathrm{e}}, \% ; R_{\mathrm{d}}$ : Content of ginsenoside $R_{\mathrm{d}}, \% ; R_{\mathrm{b} 1}$ : Content of ginsenoside $R_{\mathrm{b} 1}, \%$. Different letters indicate significant differences between samples ( $p<0.05$ ). The following is same.

Figure 6 Contents of the ginsenoside $R_{1}, R_{\mathrm{g} 1}, R_{\mathrm{e}}, R_{\mathrm{d}}, R_{\mathrm{b} 1}$, and PNS of raw, IR-HAD, and HAD Panax Notoginseng roots

There was no significant difference in saponin content under different radiation distances (Figure 6b). The contents of ginsenoside $R_{1}, R_{\mathrm{e}}, R_{\mathrm{d}}, R_{\mathrm{b} 1}$, and PNS decreased as IR-HAD radiation power increased from 675 to $2025 \mathrm{~W}$ under the constant radiation distance of $10 \mathrm{~cm}$ and drying temperature of $50^{\circ} \mathrm{C}$, as shown in Figure 6c. Nevertheless, the contents of ginsenoside $R_{\mathrm{g} 1}$ firstly increased and then decreased gradually. This may be due to the change of radiation power, which changes the amount of radiation energy and indirectly affects the material temperature. When the radiation power was $2025 \mathrm{~W}$, the radiation energy was too high, which led to a significant decrease in ginsenosides contents. Gabel et al. ${ }^{[62]}$ pointed out that the increase of infrared power will also cause the increase of chlorophyll content in dried onion.

\subsection{Rehydration ratio of dried Panax notoginseng roots}

The rehydration capacities of Panax notoginseng roots dried at different conditions are presented in Figure 7. The increase in drying temperature resulted in poorer rehydration performance due to more damage in cellular integrity and structure collapse during drying ${ }^{[63,64]}$. However, the highest temperature of $55^{\circ} \mathrm{C}$ facilitated rehydration, similar to the findings reported by Wang et al. ${ }^{[44]}$ on pulsed vacuum dried lemon slices. This phenomenon indicated that structure porous caused by the fast moisture removal at high temperature could provide a good path for the infiltration of water into the dried samples. The rehydration ratio of the infrared drying sample is significantly higher than that of hot air drying sample, which also confirms that infrared radiation drying is conducive to the formation of porous structure (Figure 8). Higher water absorption capacity was related to a larger radiation distance, with a significant difference between $160 \mathrm{~mm}$ and the other two $(p<0.05)$. The reason may be that rapid and intense thermal generated inside the material by IR radiation resulting from the 
decreased radiation distance would cause more severe heat damage, thereby lower rehydration capability, which agreed with the report of Salarikia et al. ${ }^{[65]}$. Moreover, a lower radiation power of $675 \mathrm{~W}$, produced a smaller penetration depth, helped maintain a significantly higher $R R$ value compared to the higher radiation power, which confirmed that significantly higher intensity radiation of Panax notoginseng roots to the thermal environment and ununiform heating process would cause severe tissue collapse.

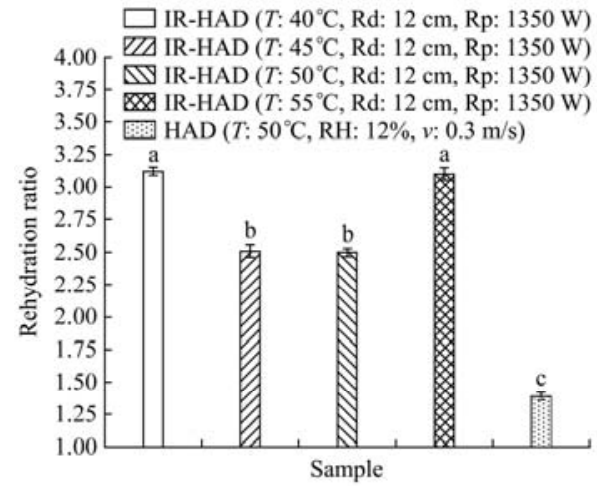

a. IR-HAD at different drying temperatures, constant radiation distances and radiation powers

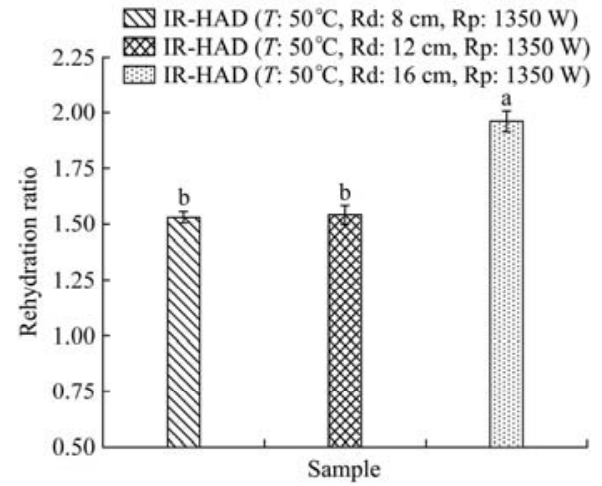

b. IR-HAD at different radiation distance, constant drying temperature and radiation power

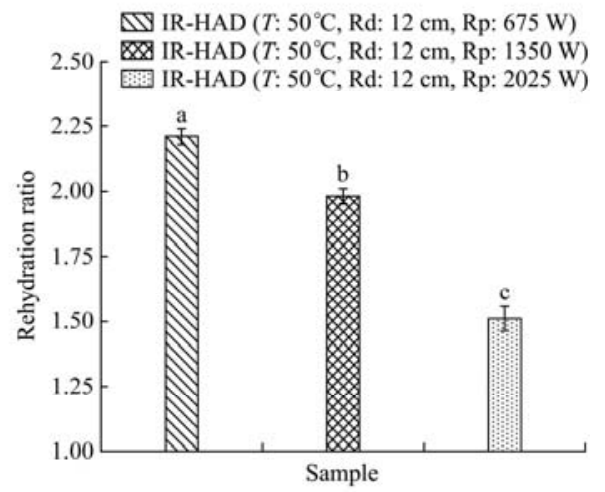

c. IR-HAD at different radiation power, constant drying temperature and radiation distance

Figure 7 Rehydration ratio of IR-HAD and HAD Panax notoginseng roots

\subsection{Microstructure of dried Panax notoginseng roots}

The microstructures of samples dried at different drying temperatures by IR-HAD or HAD at a constant radiation distance of $12 \mathrm{~cm}$ and radiation power of $1350 \mathrm{~W}$ were observed using SEM. The cross-sectional morphology of Panax notoginseng roots dried at different drying technologies are shown in Figures $8 \mathrm{a}-8 \mathrm{e}$ in $\times 100$ magnification. From Figures 8a-8c, the homogeneous pore size and distribution can be observed in the ginseng root slices dried by IR-HAD at $40^{\circ} \mathrm{C}, 45^{\circ} \mathrm{C}$, and $50^{\circ} \mathrm{C}$. The better distribution of pore can help to maintain volume and shape in the plant tissues, which is consistent with the results of others ${ }^{[38]}$. Obviously, Panax

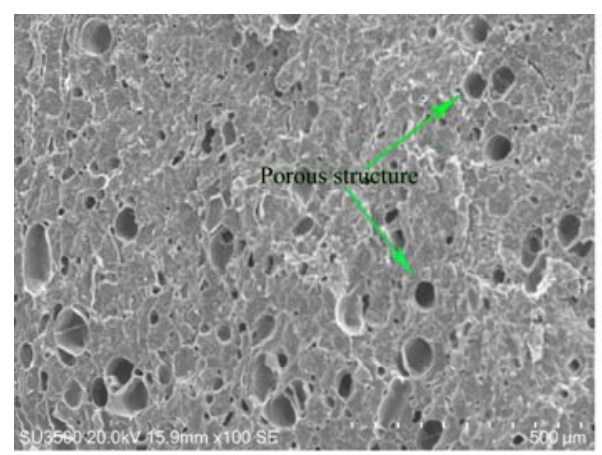

a. IR-HAD ( $T: 40^{\circ} \mathrm{C}$; Rd: $12 \mathrm{~cm}$; Rp: $\left.1350 \mathrm{~W}\right)$

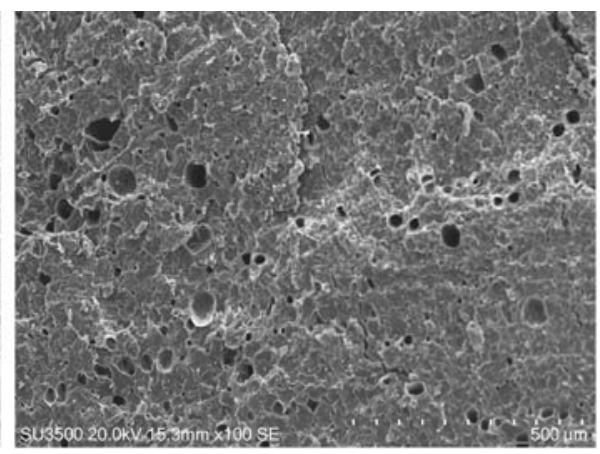

b. IR-HAD ( $T: 45^{\circ} \mathrm{C}$; Rd: $12 \mathrm{~cm}$; Rp: $\left.1350 \mathrm{~W}\right)$ notoginseng roots dried by IR-HAD at $55^{\circ} \mathrm{C}$ exhibited a large collapse structure, while a gel layer on the surface of the sample dried by $\mathrm{HAD}$ at $50^{\circ} \mathrm{C}$. The more porous space and pore distribution can be observed in the dried samples under IR-HAD compared to that in the samples dried by HAD. This might be because the sample surface absorbed IR energy, resulting in the occurrence of some swelling or deformation in the plant tissue, especially the rapid moisture evaporation at high drying temperatures. These observations correlated well with the findings of Nowak and Lewicki ${ }^{[66]}$ on IR dried apple slices. This phenomenon of SEM is identical to the results of rehydration ratio $(R R)$.

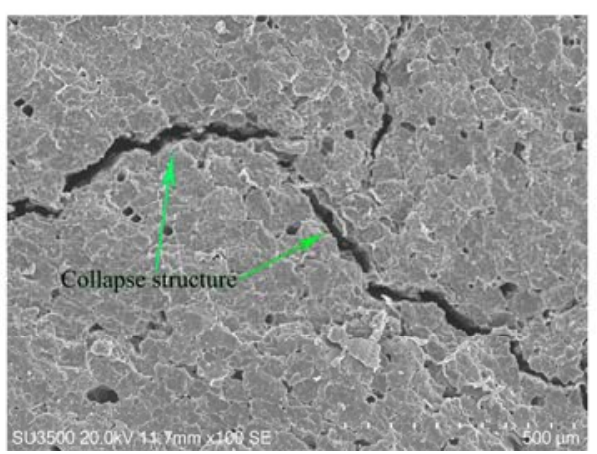

d. IR-HAD ( $T: 55^{\circ} \mathrm{C}$; Rd: $12 \mathrm{~cm}$; Rp: $\left.1350 \mathrm{~W}\right)$

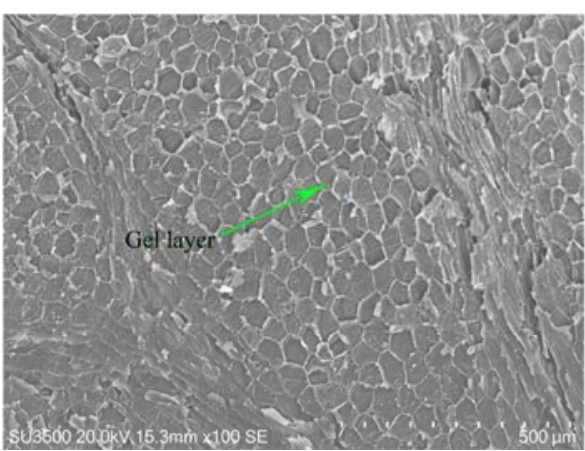

e. $\operatorname{HAD}\left(T: 50^{\circ} \mathrm{C} ; \mathrm{RH}: 12 \% ; v: 0.3 \mathrm{~m} / \mathrm{s}\right)$

Figure 8 SEM images of IR-HAD and HAD of Panax notoginseng roots under different drying conditions

\subsection{Energy consumption analysis}

Figure 9 indicates the specific energy consumption of Panax notoginseng roots dried by different drying conditions. The mean energy consumption was $28.0,22.5,18.7$ and $15.9 \mathrm{~kW} \cdot \mathrm{h} /(\mathrm{kg}$-water) under IR-HAD at $40^{\circ} \mathrm{C}, 45^{\circ} \mathrm{C}, 50^{\circ} \mathrm{C}$, and $55^{\circ} \mathrm{C}$, constant radiation distance at $12 \mathrm{~cm}$ and constant radiation power at $1350 \mathrm{~W}$, respectively. The results illustrated that the specific energy consumption decreased with the increase in the drying temperature. The high drying temperatures accelerated heat transfer and it increased the drying rate and decreased the energy consumption. 
The results are similar to $\mathrm{Li}$ et al. ${ }^{[67]}$ who investigated IR for Mountain ginseng slices. The specific energy consumption of the IR-HAD dried samples was lower than that of the HAD dried samples at the same drying temperature. At the same drying temperature of $50^{\circ} \mathrm{C}$, the specific energy consumption of samples dried by HAD was $24 \mathrm{~kW} \cdot \mathrm{h} /(\mathrm{kg}$-water). The energy-saving ratio of $22.1 \%$ could be reached compared between the IR-HAD samples with the HAD dried samples. This result may be explained by the fact that the heat efficiency of IR-HAD drying is high and the drying rate of IR-HAD is faster than that of the HAD drying.

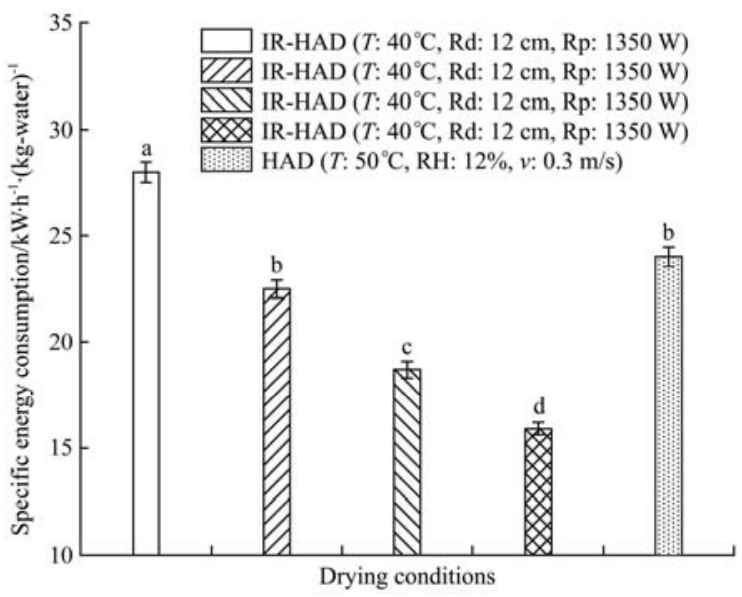

a. IR-HAD at different drying temperatures, constant radiation distance and radiation power

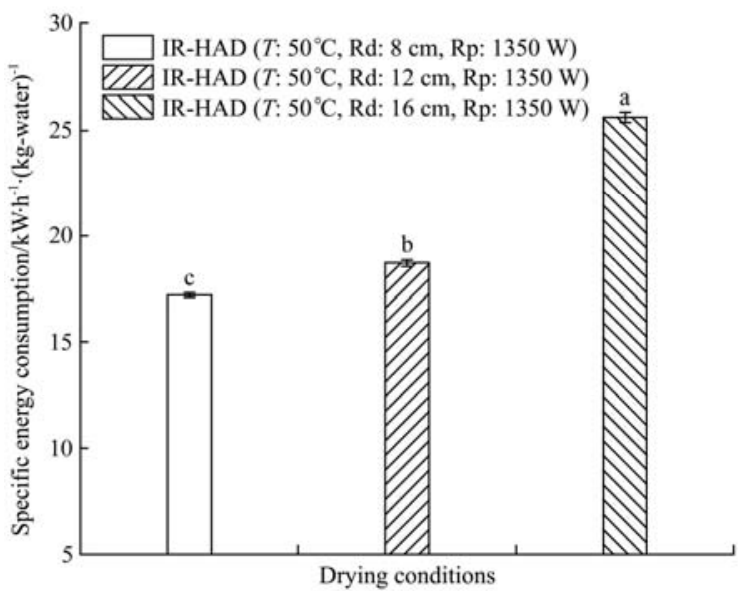

b. IR-HAD at different radiation distance, constant drying temperature and radiation power

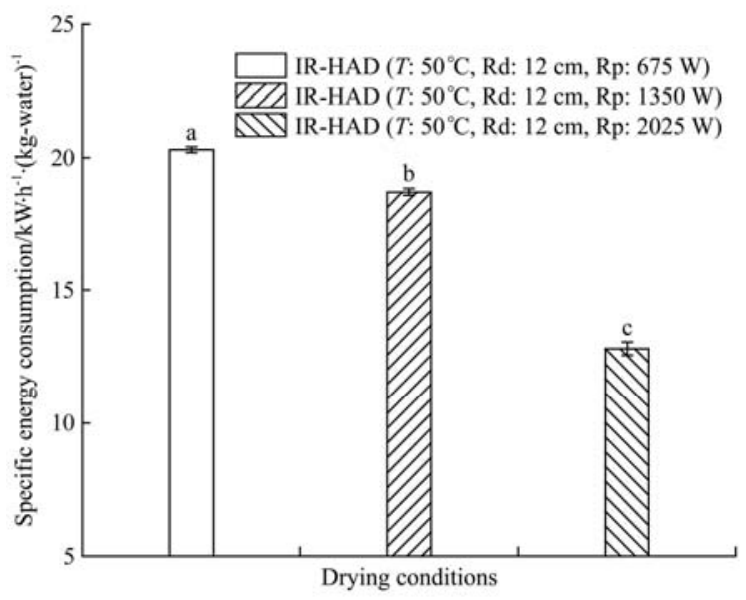

c. IR-HAD at different radiation power, constant drying temperature and radiation distance

Figure 9 Specific energy consumption during drying of Panax notoginseng roots under different IR-HAD or HAD conditions
The specific energy consumption increased from 17.2 to $25.6 \mathrm{~kW} \cdot \mathrm{h} /(\mathrm{kg}$-water) as radiation distance increased from 8 to $12 \mathrm{~cm}$. On the contrary, the specific energy consumption decreased from 20.3 to $12.8 \mathrm{~kW} \cdot \mathrm{h} /(\mathrm{kg}$-water) as radiation power increased from 675 to $2025 \mathrm{~W}$. This may be due to the significant correlation between infrared radiation energy and radiation distance and radiation power. Stronger radiation energy can accelerate drying rate and shorten drying time ${ }^{[43]}$. The results of specific energy consumption were also confirmed in the drying kinetic curve (Figures 3-5).

\section{Conclusions}

The drying methods and drying temperatures have a significant impact on drying characteristics and quality attributes of whole Panax notoginseng roots. The results indicated that the increase of drying temperature reduced drying time and energy consumption. The shortest drying time of $43.0 \mathrm{~h}$ and lowest specific energy consumption of $15.9 \mathrm{~kW} \cdot \mathrm{h} /(\mathrm{kg}$-water) were reached by IR-HAD at $55^{\circ} \mathrm{C}$. With the decrease of radiation distance and the increase of radiation power, the drying time was significantly shortened. However, a high drying temperature resulted in a high color difference, a large collapse structure, and rehydration of Panax notoginseng roots. The drying time of Panax notoginseng roots dried by IR-HAD at a drying temperature of $50^{\circ} \mathrm{C}$ was much shorter $(15.5 \%)$ than HAD at the same drying temperature. The contents of $R_{1}, R_{\mathrm{g} 1}, R_{\mathrm{e}}, R_{\mathrm{b} 1}$, and PNS were higher when the samples were dried by IR-HAD than the samples dried by HAD at the same temperature of $50^{\circ} \mathrm{C}$. Moreover, compared to HAD, the IR-HAD dried samples shorten $15.5 \%$ drying time and save $22.1 \%$ energy consumption. Radiation distance and radiation power had no significant effect on ginsenosides content. Therefore, the optimal processing condition was Panax notoginseng roots under IR-HAD at drying temperature of $50^{\circ} \mathrm{C}$, radiation distance of $12 \mathrm{~cm}$ and radiation power of $1350 \mathrm{~W}$, which can shorten drying time, maintain high ginsenosides contents and satisfactory apparent qualities.

\section{Acknowledgments}

This work was financially supported by China Agriculture Research System (CARS-21).

\section{[References]}

[1] Bai T Y. Medium and short wave infrared drying characteristics and quality of Panax notoginseng. Master dissertation. Beijing: China Agricultural University, 2019; 81p. (in Chinese)

[2] FAO stat database, 2020. Available: http://faostat.fao.org. Accessed on [2020-9-30].

[3] Zhang F X, Tang S J, Zhao L, Yang X S, Yao Y, Hou Z H, et al. Stem-leaves of Panax as a rich and sustainable source of less-polar ginsenosides: comparison of ginsenosides from Panax ginseng, American ginseng and Panax notoginseng prepared by heating and acid treatment. Journal of Ginseng Research, 2020; 45(1): 163-175.

[4] Palada M C, Crossman S. Planting density affects growth and yield of bush okra. In: 34th Annual Meeting, Jamaica: Caribbean Food Crops Society, 1998; Paper number: 256800. doi: 10.22004/ag.econ.256800.

[5] Davidson V J, Martynenko A I, Parhar N K, Sidahmed M, Brown R B. Forced-air drying of ginseng root: Pilot-scale control system for three-stage process. Drying Technology, 2009; 27(3): 451-458.

[6] Lu Z J, Zheng X G. Effect of Panax notoginsenosides on apoptosis and apoptosis controlling gene in vascular endothelial cell. Chinese Journal of Integrative Medicine on Cardio-/Cerebrovascular Disease, 2005; 11: 3. (in Chinese)

[7] Karabulut I, Topcu A, Duran A, Turan S, Bülent O. Effect of hot air drying and sun drying on color values and $\beta$-carotene content of apricot 
(Prunus armenica L.). LWT - Food Science and Technology, 2007; 40(5): 753-758.

[8] Jiang D L, Li C C, Zielinska S, Liu Y H, Gao Z J, Wang R Y, et al. Process performance and quality attributes of temperature and step-down relative humidity controlled hot air drying of Panax notoginseng roots. Journal of Ginseng Research, 2021; 14(6): 244-257.

[9] Xiao H W, Bai J W, Xie L, Sun D W, Gao Z J. Thin-layer air impingement drying enhances drying rate of American ginseng (Panax quinquefolium L.) slices with quality attributes considered. Food and Bioproducts Processing, 2015; 94: 581-591.

[10] Zhao H Y. Hot air drying characteristics and quelity of American ginseng based on being controlled temperature and humidity. Master dissertation. Beijing: China Agricultural University, 2016; 99p. (in Chinese)

[11] Ju H Y, Zhao S H, Mujumdar A S, Zhao H Y, Duan X, Zheng Z A, et al. Step-down relative humidity convective air drying strategy to enhance drying kinetics, efficiency, and quality of American ginseng root (Panax Quinquefolium). Drying Technology, 2019; 36: 1-14.

[12] Karunasena H C P, Gu Y T, Brown R J, Senadeera W. Numerical investigation of case hardening of plant tissue during drying and its influence on the cellular-level shrinkage. Drying Technology, 2015; 33(6): 713-734.

[13] Gulati T, Datta A K. Mechanistic understanding of case-hardening and texture development during drying of food materials. Journal of Food Engineering, 2015; 166: 119-138.

[14] Du X W, Wills R B H, Stuart D L. Changes in neutral and malonyl ginsenosides in American ginseng (Panax Quinquefolium) during drying, storage and ethanolic extraction. Food Chemistry, 2004; 86: 155-159.

[15] Dai J W, Rao J Q, Wang D, Xie L, Xiao H W, Liu Y H, et al. Process-based drying temperature and humidity integration control enhances drying kinetics of apricot halves. Drying Technology, 2015; 33 : 365-376.

[16] Ju H Y, El-Mashad H M, Fang X M, Pan Z, Xiao H W, Liu Y H, et al. Drying characteristics and modeling of yam slices under different relative humidity conditions. Drying Technology, 2016, 34: 296-306.

[17] Ju H Y, Xiao H W, Zheng X, Guo X L, Liu Y H, Zhang W P, et al. Effect of hot air relative humidity on drying characteristics of carrot slabs. Transactions of the CSAE, 2015; 31(16): 296-304. (in Chinese).

[18] National Pharmacopoeia Committee. Pharmacopoeia of People's Republic of China, Part 1. Chemical Industry Press: Beijing, 2015; 1: $11-15$.

[19] Wang J, Fang X M, Mujumdar A S, Qian J Y, Zhang Q, Yang X H, et al. Effect of high-humidity hot air impingement blanching (HHAIB) on drying and quality of red pepper (Capsicum Annuum L.). Food Chemistry, 2017; 220: $145-152$.

[20] Chen L, Subbiah J, Jones D, Zhao Y Y, Jung J. Development of effective drying strategy with a combination of radio frequency (RF) and convective hot-air drying for inshell hazelnuts and enhancement of nut quality. Innovative Food Science \& Emerging Technologies, 2020; 67: 102555. doi: 10.1016/j.ifset.2020.102555.

[21] Zhang B, Zheng A J, Zhou L Y, Huang Z, Wang S J. Developing hot air-assisted radio frequency drying for in-shell walnuts. Emirates Journal of Food and Agriculture, 2016; 28(7): 459-467.

[22] Rattanadecho P, Makul N. Microwave-assisted drying: A review of the state-of-the-art. Drying Technology, 2015; 34(1): 1-38.

[23] Khir R, Pan Z, Salim A, Hartsough B R, Mohamed S. Moisture diffusivity of rough rice under infrared radiation drying. LWT-Food Science and Technology, 2011; 44 (4): 1126-1132.

[24] Ju H Y, Xiao H W, Bai J W, Xie L, Lou Z, Gao Z J. Medium and short wave infrared drying characteristics and color changing of apple slices. Transactions of the CSAM, 2013; 44 (S2): 186-191. (in Chinese)

[25] Barzegar M, Zare D, Stroshine R L. An integrated energy and quality approach to optimization of green peas drying in a hot air infrared-assisted vibratory bed dryer. Journal of Food Engineering, 2015; 166: 302-315.

[26] Adak N, Heybeli N, Ertekin C. Infrared drying of strawberry. Food Chemistry, 2017; 219: 109-116.

[27] Rao J Q, Xie Y C, Kladniama K, Lin Y W, Xie Y, Gao Z J, et al. Combined mid-infrared and hot air impingement drying of cucumber slices. In: ASABE Annual International Meeting, Orlando, USA. 2016, 24(6): 55-58. doi: 10.13031/aim.20162460058

[28] Onwude D I, Hashim N, Abdan K, Janius R, Chen G, Kumar C. Modelling of coupled heat and mass transfer for combined infrared and hot-air drying of sweet potato. Journal of Food Engineering, 2018; 228: $12-24$.
[29] Doymaz I. Infrared drying kinetics and quality characteristics of carrot slices. Journal of Food Processing and Preservation, 2015; 39(6): 273-275.

[30] Puente-Diaz L, Ah-Hen K, Vega-Galvez A, Lemus-Mondaca R, Di Scala K Combined infrared-convective drying of murta (Ugni molinae Turcz) berries: Kinetic modeling and quality assessment. Drying Technology, 2013; 31(3): 329-338.

[31] Riadh M H, Ahmad S A B, Marhaban M H, Soh A C. Infrared heating in food drying: An overview. Drying Technology, 2015; 33(3): 322-335.

[32] Hebbar H U, Vishwanathan K H, Ramesh M N. Development of combined infrared and hot air dryer for vegetables. Journal of Food Engineering, 2004; 65(4): 557-563.

[33] Bi J, Chen Q, Zhou Y, Liu X, Wu X, Chen R. Optimization of short- and medium-wave infrared drying and quality evaluation of jujube powder. Food and Bioprocess Technology, 2014; 7(8): 2375-2387.

[34] Qu C, Bai Y, Jin X, Wang Y, Zhang K, You J Y, et al. Study on ginsenosides in different parts and ages of Panax Quinquefolius L. Food Chemistry, 2009; 115: 340-356.

[35] Chen J K, Lin H T, Lin Y F, Li H, Wang Z Y. Optimized technology of pleurotus eryngii by Mmcrowave-vacuum drying based on quality and energy consumption. Transactions of the CSAE, 2014; 30(3): 277-284. (in Chinese).

[36] Jiang D L, Xiao H W, Zielinska M, Zhu G F, Bai T Y, Zheng Z A. Effect of pulsed vacuum drying on drying kinetics and quality of roots of Panax Notoginseng (burk.) F. H. Chen (Araliaceae). Drying Technology, 2020; 10: $153-162$.

[37] Liu Y, Duan Z, Sabadash S. Effect of hot air drying temperatures on drying characteristics and physicochemical properties of beetroot (Beta vulgaris) slices. IOP Conference Series: Earth and Environmental Science, 2020; 615(1): 012099. doi: 10.1088/1755-1315/615/1/012099.

[38] Xiao H W, Bai J W, Xie L, Sun D W, Gao Z J. Thin-layer air impingement drying enhances drying rate of American ginseng (Panax quinquefolium L.) slices with quality attributes considered. Food \& Bioproducts Processing, 2015, 94: 581-591.

[39] Xiao H W, Gao Z J. The application of scanning electron microscope (SEM) to study the microstructure changes in the field of agricultural products drying. In: Kazmiruk V (Ed.) Scanning Electron Microscopy, Rijeka, Croatia: IntechOpen, 2012; pp: 213-226.

[40] Ding C, Khir R, Pan Z, Zhang J, Tu K, El-Mashad H. Effect of infrared and conventional drying methods on physicochemical characteristics of stored white rice. Cereal Chemistry, 2015; 92(5): 441-448.

[41] Ning X, Han C. Drying characteristics and quality of taegeuk ginseng (Panax ginseng C.A. Meyer) using far-infrared rays. International Journal of Food Science \& Technology, 2013; 48(3): 477-483.

[42] Roknul A S M, Zhang M, Mujumdar A S, Wang, Y. A Comparative study of four drying methods on drying time and quality characteristics of stem lettuce slices ( Lactuca sativa L.). Drying Technology, 2014; 32(6): 657-666.

[43] Zhang Y, Zhu G F, Li X Y, Zhao Y, Lei D W, Ding G Q, et al. Combined medium- and short-wave infrared and hot air impingement drying of sponge gourd (Luffa cylindrical) slices. Journal of Food Engineering, 2020; 284: 110043. doi: 10.1016/j.foodeng.2020.110043.

[44] Wang J, Law C L, Nema P K, Zhao J H, Liu Z L, Deng L Z, et al. Pulsed vacuum drying enhances drying kinetics and quality of lemon slices. Journal of Food Engineering, 2018; 224: 129-138.

[45] Ranjan R, Irudayaraj J, Reddy J N, Mujumdar A S. Finite-element simulation and validation of stepwise drying of bananas. Numerical Heat Transfer, Part A: Applications, 2004; 45(10): 997-1012.

[46] Zheng X, Xiao H W, Wang L, Zhang Q, Bai J W, Xie L, et al. Shorting drying time of Hami-melon slice using infrared radiation combined with air impingement drying. Transactions of the CSAE, 2014; 30(1): 262-269. (in Chinese).

[47] Nowak D, Lewicki P P. Infrared drying of apple slices. Innovative Food Science \& Emerging Technologies, 2004; 5(3): 353-360.

[48] Miraei Ashtiani S H, Salarikia A, Golzarian M R. Analyzing drying characteristics and modeling of thin layers of peppermint leaves under hot-air and infrared treatments. Information Processing in Agriculture, 2017; 4 (2): 128-139.

[49] Tysen A, Vomhoff H, Nilsson L. Through air drying assisted by infrared radiation: the influence of radiator power on drying rates and temperature. Nordic Pulp \& Paper Research Journal, 2018; 33(4); 581-591.

[50] Ghaboos S H H, Ardabili S M S, Kashaninejad M, Asadi G, Aalami M. Combined infrared-vacuum drying of pumpkin slices. Journal of Food Science \& Technology, 2016; 53(5): 2380-2388. 
[51] Onwude D I, Hashim N, Abdan K, Janius R, Chen G. The effectiveness of combined infrared and hot-air drying strategies for sweet potato. Journal of Food Engineering, 2019; 241, 75-87.

[52] Xiao H W, Law C L, Sun D W, Gao Z J. Color change kinetics of American ginseng (Panax quinquefolium) slices during air impingement drying. Drying Technology, 2014; 32(4): 418-427.

[53] Liu D, Li Y G, Xu H, Sun S Q, Wang Z T. Differentiation of the root of cultivated ginseng, mountain cultivated ginseng and mountain wild ginseng using FT-IR and two-dimensional correlation IR spectroscopy. Journal of Molecular Structure, 2008; 883: 228-235.

[54] Li X G, Zheng Y N, Liu M X, Zhang L L. A study on Maillard reaction and its products during processing of red ginseng. China Journal of Chinese Materia Medica, 1997; 24(5): 274-278, 318. (in Chinese)

[55] Yu Y J, Saramaki T, Yong C L. An iterative method for optimizing FIR filters synthesized using the two-stage frequency-response masking technique. In: 2003 IEEE International Symposium on Circuits and Systems (ISCAS). Bangkok, Thailand: IEEE, 2003; Paper No. 7776234. doi: 10.1109/ISCAS.2003.1205159.

[56] Pekke M A, Pan Z L, Atungulu G G, Smith G, Thompson J. Drying characteristics and quality of bananas under infrared radiation heating. Int J. Agric \& Biol Eng, 2013; 6(3): 58-70.

[57] Guo H. Research on drying characteristics and mass transfer model of Yunnan Panax notoginseng. Master dissertation, Kunming University of Science and Technology, Yunnan, China, 2015; 75p. (in Chinese)

[58] Du X W, Zhou J, Li B, Zhao G A, Bai T Z. Analysis of ginsenosides and carbohydrates in steaming products of american ginseng. Acta Chinese
Medicine and Pharmacology, 2005; 2: 3-5, 72 .

[59] Zhou J. Systematic studies on quality standard and processing method of American ginseng. Master dissertation. Heilongjiang University of Chinese Medicine, Heilongjiang, China, 2005; 96p. (in Chinese)

[60] Ning X, Lee J, Han C. Drying characteristics and quality of red ginseng using far-infrared rays. Journal of Ginseng Research, 2015; 39(4): 371-375.

[61] Vishwanathan K H, Hebbar H U, Raghavarao K. Hot air assisted infrared drying of vegetables and its quality. Food Science \& Technology Research, 2010; 16(5): 381-388

[62] Gabel M M, Pan Z, Amaratunga K S P, Harris L J, Thompson J F. Catalytic infrared dehydration of onions. Journal of Food Science, 2010; 71(9): E351-E357.

[63] Doymaz I. Infrared drying kinetics and quality characteristics of carrot slices. Journal of Food Processing and Preservation, 2015; 39(6): 2738-2745.

[64] Xie Y C, Gao Z J, Liu Y H, Xiao H W. Pulsed vacuum drying of rhizoma dioscoreae slices. LWT-Food Science and Technology, 2017; 80: 237-249.

[65] Salarikia A, Miraei Ashtiani S H, Golzarian M R. Comparison of drying characteristics and quality of peppermint leaves using different drying methods. Journal of Food Processing and Preservation, 2017; 41: 29-30.

[66] Nowak D, Lewicki P P. Quality of infrared dried apple slices. Drying Technology, 2005; 23: 831-846.

[67] Li H, Kwang T-H, Ning X F, Cho S C, Han C-S. Far infrared rays drying characteristics of tissue cultured mountain ginseng roots. Biosystems Engineering, 2009; 34(3): 175-182. (in Korean) 